City University of New York (CUNY) CUNY Academic Works

\title{
Virtual reference amid COVID-19 campus closure: a case study and assessment
}

Maureen Garvey

CUNY College of Staten Island

\section{How does access to this work benefit you? Let us know!}

More information about this work at: https://academicworks.cuny.edu/si_pubs/227

Discover additional works at: https://academicworks.cuny.edu

This work is made publicly available by the City University of New York (CUNY).

Contact: AcademicWorks@cuny.edu 


\title{
Virtual reference amid COVID-19 campus closure: a case study and assessment
}

\author{
Maureen Garvey \\ Library, College of Staten Island, Staten Island, New York, USA
}

\begin{abstract}
Purpose - This case study was conducted to assess and make changes to the consortial virtual reference service for the remainder of the period of fully virtual reference (campus closure); a second objective was to consider implications for service design and delivery upon the eventual return to the physical campus.

Design/methodology/approach - This paper begins by introducing the institution, reference practices prior to the pandemic and the changes to reference service necessitated by the campus closure. After a literature review of material related to reference and the pandemic, several years of virtual reference service data are analyzed.

Findings - The use of consortial virtual reference service has significantly increased in the pandemic, as demonstrated by questions asked by users and questions answered by librarians. Changes to work practices based on these data have been made.

Originality/value - This work is original in that it relates to the physical closure of the campus due to the pandemic, about which, to date, little has been published specifically concerning the design and delivery of reference services.
\end{abstract}

Keywords Academic libraries, Reference services, Distance learning, Case study, Virtual reference, Pandemic Paper type Case study

\section{Introduction}

During the first week of March 2020, news came that the coronavirus (which was rapidly spreading around the world) had entered New York City. For most institutions of higher learning, in North America and around the world, it was both a challenging and a tense period in which the decision to close campuses was being weighed, with relevant information changing rapidly. Institutions of higher education began to announce temporary closures or temporary moves to online learning (which in most cases lasted far longer than temporarily). This case study is an account of virtual reference services in the wake of the coronavirus disease 2019 (COVID-19) pandemic at the College of Staten Island (CSI), one of 11 senior colleges of the City University of New York (CUNY). Like others in higher education, the CSI administration initially endeavored to keep certain services open, including the library, while moving to remote learning. This attempt was abandoned when New York State Governor Andrew Cuomo announced stay-at-home orders (PAUSE) on March 20th, at which point CSI's campus officially closed. All CSI Library instruction moved online. All reference service became virtual. The temporary closure became the status quo for CSI Library - it remains closed until Fall 2021 when there are plans for a limited reopening. The CSI Library's closure presents a unique opportunity to analyze service points under a different lens in the absence of in-person services. Although virtual chat existed prior to March 2020, the standard and predominant delivery method for reference at CSI Library was in-person.

This article presents a case study focused on CSI Library's virtual reference service data in the wake of the pandemic and offers a reassessment of future services based on an in-depth analysis of chat reference data captured between 2014 and 2020. To contextualize, the paper begins with an introduction to CSI, its users and its library services. The discussion of CSI Library's reference service before the pandemic and the changes necessitated by the campus 
closure due to COVID-19 follows. After reviewing the current literature on the pandemic and its effects on reference, the paper analyzes several years of CSI Library's virtual reference statistics data, both before and during the pandemic. The paper concludes with a description of the changes that have been made to reference services and looks to a future defined by a continued focus on virtual reference and a return to staffing the reference desk on campus.

The CSI is a uniquely open-enrollment comprehensive college offering associate, bachelor and doctoral degrees. It is a senior college in the 25-college CUNY system, the largest urban public university in the USA [1]. It is the only public four-year higher education institution on Staten Island. As such, it takes its role in borough stewardship very seriously; the college's community role is embedded in the Vision statement and is Priority Three in the Strategic Plan 2017-2022 [2]. The CSI Library also refers to this borough stewardship role and Priority Three in its' Mission Statement [3].

The community served by CSI includes people of low-income, first generation college students, immigrants and children of immigrants. With $25 \%$ of the student body identifying as Hispanic, it is a designated Hispanic Serving Institution as of March 2019. 45.3\% of students identified as White, $13.5 \%$ Black and $11 \%$ Asian [4]. Many CSI students work while studying. It is a commuter school. The Fall 2020 FTE was 10,907 [5]. For a snapshot of the CUNY student body, here are some facts from the University Student Data Book for Fall 2019 about CUNY undergraduates [6]:

(1) $25.4 \%$ - 25 years of age or older;

(2) $35 \%$ born outside the US mainland;

(3) 202 ancestries, with 158 languages spoken;

(4) $38.6 \%$ native language other than English;

(5) $60.5 \%$ neither of the parent graduated college;

(6) $55.8 \%$ work for pay, more than half of whom work over $20 \mathrm{~h}$ per week.

These demographics underscore CSI Library's commitment to providing strong reference services to students who are likely to be first-generation college students, and who work part or full time, who often take care of children or elder family members while in school, and who, given the college's open admissions policy, may not be college-ready when they start as freshmen.

The CSI Library [7] occupies a central location on the 204-acre campus, which itself is situated in the middle of Staten Island. The CSI Library occupies most of its building which also contains other student services including a tutoring center, two computer labs and a café. The library theater is located in the entrance hall; the theater can be booked for film viewings and events. The hall leads to a central rotunda with adjacent circulation and reserve services, and a small gallery space. Continuing through the rotunda brings users to a large reference desk which is an anchor or focal point to the whole first floor. Behind it are the reference stacks and long study tables. The second floor contains computers, small tables, group study rooms for booking, the library classroom and the Archive and Special Collections. The third floor is for silent study and holds computers and the open circulating stacks containing over 500,000 volumes.

CUNY librarians are faculty members and serve on campus and university committees. CSI librarians are engaged members of the campus, providing over 200 one-shot instruction sessions in the academic year and teaching five sections of the 1 credit elective information literacy course each semester. A significant emphasis is placed on information literacy and research instruction and reference: half of the full-time CSI librarians are instructors, while also carrying other areas of responsibility. All CSI librarians serve on the reference desk. 
Reference service: prior to the pandemic, and after the campus closure

This section details the reference service at CSI Library before the pandemic arrived, and the changes that were made with the sudden campus closure. A subsection outlines this detail for virtual reference specifically.

The CSI Library places a strong emphasis on reference services, both in terms of the physical design of the space, and the ways in which it is staffed. As noted above, the reference desk is very large and sits centrally on the first floor. As students walk through the rotunda, they cannot help but walk directly into the reference desk, which makes it an anchoring service point for students seeking information about anything related to the library. The desk has two workstations, both outfitted with dual screens and dual keyboards, one side publicfacing and one private, to allow for users and librarians to work together. Librarians aim to take a student-led instructional approach and, if time allows, try to teach the user the skill they need rather than finding the information to answer the query. In terms of the culture of the department, reference shifts are sacrosanct; librarians are rarely late or absent for shifts. For the physical desk, additional support was planned with the tides of the semester; there were two librarians on the desk for the first two weeks of the semester, and a backup system for librarians to ask for reinforcements from colleagues.

The CSI Library has a strong history of maintaining extended hours for students, including additional late night hours during exam periods and weekend hours all semester long. Until budget cuts in 2019, library hours were 8 a.m. to midnight on weekdays, with weekend nights ending at 10 p.m. The reference desk, physical and virtual, is staffed by 14 full-time librarians (including the Associate Dean/Chief Librarian who covers one shift per week) and 11 adjunct librarians. All librarians covering the reference desk, whether full- or part-time, have two Master's degrees: an MLS and a second degree. It was extremely rare that the physical desk was not staffed by librarians for the scheduled hours, which covered almost all opening hours - excepting for the couple of hours before weeknight closing and several hours on weekends, when the library functioned as a study hall with only public safety supervision. Due to budget cuts in recent years, these hours were reduced to a $10 \mathrm{p} . \mathrm{m}$. closing on weekdays and a 6 p.m. close on weekends, resulting in a loud student outcry, which was curtailed only by the pandemic closing campus.

There is a documented movement within reference services for a service model where library workers other than librarians staff the reference desk or librarians staff reference desks on-call only (Anderson et al., 2021, p. 3). The question of staffing the physical desk was revisited at a CSI Library department meeting several years ago, and it was almost unanimously agreed that CSI librarians should retain desk shifts. All 14 full-time librarians believe it is important that either a full- or part-time librarian is present to answer CSI students' questions at the reference desk, and now in virtual chat [8].

With the campus closure in mid-March and the move to working from home and entirely virtual services, the CSI Library made changes to the delivery of reference service. Thankfully, the CSI Library had an existing chat reference service in addition to in-person reference, which will be described in the section below in detail. Nearly every aspect of library services needed to be swiftly retooled for fully online service. The E-Resources and Acquisitions team drafted a guide, Resources for Learning and Teaching Remotely [9], which listed a collection of temporary free licenses offered to higher education institutions. The Instruction Coordinator collected a pool of existing and newly created instructional videos on conducting research through the CSI Library and coordinated the creation of online tutorials for students and faculty. A colleague created a bibliography on pedagogy and online learning [10]. A subcommittee posted and distributed a statement on access to textbooks, explaining to faculty and students that academic publishers restrict institutional licenses in favor of individual purchases, and encouraging the use of older, cheaper editions and the exploration of open resources, whether open access (OA) or open educational resource (OER) [11]. CSI reference amid campus closure 
Librarians started using Slack, creating channels for topics, as a way to keep in touch and replicate the office environment while working remotely. It became apparent that reference services could not merely default to the existing virtual chat service model without assessing and recalibrating how chat services were reaching our students and how reference librarians at CSI were meeting those needs. The next section describes CSI Library's pre-existing virtual reference service and what changed during the pandemic.

\section{Virtual reference, before and after}

The CSI Library began to offer virtual chat with LibraryH3lp, in the early 2000s. In 2014, the CSI Library joined with several libraries at other CUNY schools to form a cooperative and moved to OCLC's Question Point platform, including their 24/7 coverage. News of Springshare's purchase of Question Point from OCLC was announced in the summer of 2019 [12]. Springshare planned to end the product and transfer all customers to their existing virtual reference product LibChat, contained in LibAnswers. The 10 schools that were participating in the CUNY Question Point cooperative agreed to move forward with Springshare's planned migration of all Question Point customers to LibAnswers before the end of May 2020. On March 13, 2020 the CSI administration, after a week considering partial closure, decided to close the CSI Library due to the pandemic. Reference services immediately became all virtual. All campuses within CUNY closed within the following week and most remain so at least until the Fall 2021 semester. Despite the short timeframe from the closure, with much planning the reference cooperative's intended migration on May 29, 2020, to the new virtual reference platform LibAnswers, proceeded smoothly.

The 10 schools in the cooperative answer questions for their own and each other's users and for the 24/7 academic global cooperative, using the LibChat platform. The conditions of the cooperative are that each school answer, from any user, $75 \%$ of the number of questions their own users ask, and staff the 24/7 queue (or chat department, in LibAnswers terminology) for a certain number of hours weekly. In the move to fully virtual reference, CSI librarians are exceeding the $75 \%$ obligation tremendously as it is the entire reference shift, as opposed to virtual chat being done while on campus. Prior to the pandemic closure, virtual reference coverage was a part of the librarian's shift on the physical reference desk. All CSI librarians were expected to be logged into the platform but the students asking for help at the desk took precedence. The impetus for this study was to compile the data on the use of virtual reference and to see what changes in priorities and work practices can be drawn from this for the remainder of the remote work period, and possibly beyond. Before analyzing that data, the paper reviews the literature on the topic of virtual reference in the pandemic.

\section{Literature review}

At this one-year mark, research on service in academic libraries during the pandemic is now making its way through the peer-review and academic publishing process. Research on reference specifically is a subset of this. In the past few months, four academic journals on librarianship have put out calls for pandemic-related research: Collaborative Librarianship, Journal of Information Literacy [13], portal: Libraries and the Academy and this publication Reference Services Review [14]. Searching the Library and Information Science Source database for the keyword "COVID-19" returned over 3,000 items in March 2021. Refining the search to focus on full-text and peer-reviewed material with the keyword "academic" reduced this to 90 [15]. The parameters of this review are material published (1) in scholarly and trade publications, (2) since the campus closures and (3) pertaining to academic libraries and virtual reference, or on public service delivery more broadly with a substantive section on reference.

This review begins by highlighting some narratives of the response to the pandemic, including articles that parallel CSI's experience of closing and pivoting to all virtual services and provide lessons for the author's institution. Subsequently, the review determines and 
discusses three themes in the literature on the pandemic and reference service. The review concludes by considering scholarship that ties these themes to the profession more generally and focuses practitioners on where they might want to take both their reference services specifically, and their library services generally, in the future.

There are many direct narratives of responses to the pandemic, detailing decisions to close, adaptations to virtual reference and tools used by librarians, (see Weeks et al., 2020; Lindsay et al., 2021; Howes et al., 2021). In a Public Services Quarterly "Best of the literature" column Vogus (2020) provided an annotated bibliography of seven articles on virtual reference published prior to the pandemic but which help with the pivot to virtual reference now. With regard to CUNY itself, Simpson (2020) was an excellent narrative timeline of the events leading to campus closures in the CUNY system, including the view from libraries. Focused on another senior college, this timeline covered the larger administration's moves at the onset of the pandemic. It will serve as a record of the events for posterity. By September 2020, Qualitative and Quantitative Methods in Libraries (QQML) published an entire special issue on library service in the pandemic. Much was recognizable to this author in the experience of Campbell et al. (2020): ensuring the continuity of library services in the sudden move online; issues around working from home; the initial confusion and the administration's attempt to keep the library open in a limited way; and the new tools being used by library staff to provide service remotely. Mirroring the use of internal messaging while working from home, CSI librarians have taken to Slack and it may be a tool they continue to use post-reopening. Slack has additionally proved useful for virtual reference in that CSI librarians can get real-time answers from colleagues while chatting with users, and alert each other to issues that come up in the virtual "desk." Rafiq et al. (2021) also detailed practical considerations that echoed CSIs. In this survey of university libraries in Pakistan on their responses to the pandemic, similarities included the digital divide experienced by both students and staff, the increased staff workload and the need to bolster library budgets for e-resources. The authors concluded with a list of recommendations drawn from analyzing the survey responses, some of which again are useful for our institution, including lobbying to address the digital divide and improve Internet access, re-prioritizing budgets toward e-resources, considering online students' perspective in all work into the future and reviewing web presence regularly with the online student in mind. These articles help make visible the common issues that different institutions share as they are occurring. In reviewing them, themes emerge that can help to clarify and consolidate the main issues academic libraries face moving forward. Below is a discussion of three themes that arose in the literature around the impact of COVID-19 closures on reference or public services.

Beyond recounting events and addressing the immediate and practical considerations of the closures, the first major theme identifiable in the literature was the lack of access to print reserves or textbooks in the move to fully online learning (Archer-Helke et al., 2021; Dar, 2020a; Radford et al., 2021; Rafiq et al., 2021). Libraries may purchase hard copies of textbooks. However, for online access to these textbooks, many academic publishers sell only individual licenses. They do not provide institutional licenses. This is their profit model. Academic library users may not be informed about this issue and what it may mean for them. For students, this is a major barrier to accessing these necessary learning materials. For faculty, this involves extra labor to make texts accessible. Like many academic libraries, the CSI Library released a statement on this topic early in the closure. The statement encouraged faculty to explore three options, (1) finding OA or OER alternatives to textbooks that cannot be purchased by the library, (2) copyright-compliant scanning of personal copies to password-protected venues and (3) allowing students to use older editions which are more affordable. In their reference encounters, CSI librarians seek to provide solutions to the degree possible and also inform users on this issue in scholarly communications. The pandemic closures have highlighted inequity in access to learning materials. This spotlight provides a renewed focus on working to resolve this long-standing issue. 
The second theme found was extending greater compassion to students, and to ourselves (Dar, 2020a, 2020b). This theme showed up in a variety of ways. In discussing how COVID-19 transformed reference service in academic libraries, librarians at one institution noticed that patrons were quicker to drop off chat if there was even a short delay, compared to prepandemic times (Dar, 2020b). Some librarians found, as have those at CSI, that using their chat platform's version of canned messages and macros has been helpful in addressing any delay and speeding up email follow-up (Dar, 2020b). In a fast-paced, pithy column in Library Journal, "Expanding chat reference during COVID" (Dodd and Kotaska, 2020), Cornell librarians noticed local users asking questions that appeared to seek a connection to the campus. Cornell librarians ensured more local answering through their cooperative and went from answering $50-75 \%$ of their own users' questions. They responded to the impending closure by convening a Virtual Reference Response Team which allowed them to quickly organize the expanded coverage. Much of the rapid change necessitated by the pandemic has been labor-intensive for library workers. Rafiq et al. (2021) referred to the issue of increased staff workload; the following sentence could easily have been written about our institution at the beginning of the work from home period: "Library staff worked from home and there was a sense of over burden because of $24 / 7$ connectivity and without any formal working policy addressing the new working routines." Campbell et al. (2020) also spoke about these new issues working from home. Students, faculty and library workers are under the combined stresses of the sudden move to remote learning and continuing to cope with the pandemic. It can be a delicate balance for library workers at this time to respond to students needs while also looking after themselves. This theme in the literature should be considered when assessing virtual reference services and implementing changes.

The third theme was the future. While the pandemic, the closures and some of the changes in reference service models will be temporary, academic libraries are considering what adjustments from this period they might want to retain, and drawing on lessons from the pandemic closure, what adjustments they might want to make to improve both service models and quality of work-life. The Public Services Committee of the Consortium of Academic and Research Libraries in Illinois (CARLI) held a program on this subject in January 2021 (Archer-Helke et al., 2021). This forum for the 129 member libraries provided an opportunity to discuss "the changes in services that should be retained post-COVID-19; and changes in outreach due to COVID-19 and how they will affect future outreach practices." Koos et al. (2021) provided a comprehensive overview of changes made and what will be retained postpandemic at a SUNY medical school library. They acknowledged that technological improvements they had made in 2019 allowed them to provide their frontline clinician users with access to the space throughout the pandemic but all reference service was virtual. A study at Toronto University on continuity of service had an eye to the long-term"while emergency measures taken to maintain library services may ordinarily be implemented temporarily, it is worth considering which measures enacted in response to this emergency may have a lasting effect, as well as what further changes may come for libraries in a post-pandemic world" (Walsh and Rana, 2020). Below the discussion moves on to scholarship that ties these themes to the profession more generally and focuses practitioners on where libraries might want to take their services in the future.

Continuing the two latter themes of empathy and focus on the future, Anderson et al. were more theoretical in scope and tied virtual reference to larger issues within the field. In "Library consultations and a global pandemic: An analysis of consultation difficulty during COVID-19 across multiple factors," they concluded (p. 8), "Further examination of the perceived difficulty and burden imposed by different types of patron interactions is an essential strategy for understanding how the growth of virtual reference affects librarian workload, mitigating the deleterious effects of librarian burnout and low morale, and maintaining high-quality public services during facility closures or changes in service models.” 
Brown's entry in the $Q Q M L$ special issue, "Recalibrating librarians' service ethic in the COVID 19 pandemic: Towards a mutually empowering framework" also related to these two themes of empathy and the profession into the future and influenced the author's thinking from this larger perspective. Brown argued that this exceptional event of the pandemic has thrown into sharp relief the contradictory ways society views libraries and their workers and suggested we use this time to critically reassess our deeply held service ethos and the subservience that may be tied to it. Libraries, and their staff and users, are subject to administrative actors' competing conceptions of the library as a public good vs implementing private sector customer service methods. Brown characterized librarianship as a womenintensive field as opposed to women-dominated, because while it is majority-female $(83 \%$ as of 2011, and higher in the public-facing non-managerial roles), the management level is male-dominated (Brown, 2020, p. 100; Mars, 2018; Beveridge et al., 2011). Reading Brown causes one to wonder, does the field's service (or subservience) orientation and female supermajority influence CSI maintaining librarians staffing a physical desk for so many hours, and continuing to staff the virtual desk to the point of exceeding our obligations? Advocacy for better conditions might also be aided by the professional self-reflection Brown seeks, even though this author notes these are political and labor rights issues. The pandemic may serve as an opportunity to do the recalibrating that Brown has suggested.

Foreshadowing the longer-term and more substantial studies to come, in March 2021, an item in College and Research Libraries News (Radford et al., 2021) previewed the results of a longitudinal 300-respondent survey of academic libraries. This highlighted how readers can expect different stages to the published research on libraries during the pandemic, covering shortand long-term impact. This preview touched upon all three of the themes noted above and it will be interesting to see how they are covered when the study itself is published.

Research published prior to the pandemic remains helpful in reimagining reference service models into the future. Additions to the library and information science literature in recent years (Ettarh, 2018; Galvan, 2015; Hathcock, 2015; Honma, 2005; SchlesselmanTarango, 2016) on subject matter related to empathy and the future of services, such as librarian burnout, workload management, lack of diversity, lack of inclusion, whiteness, low morale, critical librarianship and social justice are instructive when considering reference services in these unprecedented times and where we may want to take them.

There is an evident interest in the literature with how the profession views and deals with empathy, for patrons and for service providers alike. Libraries are focusing on the future of public services and using this time to review what changes might be maintained to improve future service. Harkening back to the first theme of access to learning materials, for those libraries that are planning re-openings or keeping current on mitigation, there is much guidance from our field's professional and nonprofit organizations, including the American Library Association (ALA) [16], Association of College and Research Libraries [17], International Federation of Library Associations and Institutions [18] and OCLC [19] ALA included protocols and also data and research done in the field. These materials focused more on physical handling of items and use of space when reopening, rather than virtual reference, both of which will need to be reviewed and updated upon reopening in a postpandemic workplace.

These three themes of access to learning materials, empathy and future planning can serve to inform and crystallize future research and action as more institutions move toward reopening. Detailed results from reviewing CSI's virtual reference statistics will inform the CSI Library's future planning. The following sections discuss methodology and results of the review of CSI's virtual reference statistics.

\section{Methodology}

This study analyzed the use of CSI Library's virtual reference service by its users and librarians in the pandemic closure period. The purpose of this analysis was to provide data 
with which to make decisions about the reference service model at the half-way point in the campus closure and with a view to the return to on-campus services.

To accomplish this goal, the author compiled and analyzed virtual reference statistics for the academic years 2014/2015, 2015/2016, 2017/2018, 2018/2019, 2019/2020 [20], and the summers of 2019 and 2020, and then compared these statistics to the pandemic period of MarchDecember 2020 (all data contained in Charts 1-8 with corresponding Tables 1-8). The data being compared included the number of questions that CSI users asked, and the number of questions that CSI librarians answered. CSI users' questions may be answered by anyone in the cooperative, just as CSI librarians may answer users from any institution in the co-op. To reiterate, on May 29, 2020 the CSI Library moved from Question Point to LibAnswers for its virtual reference platform, as Springshare purchased the former product and migrated all customers to the latter. Therefore, the data are taken from these two platforms.

With the move to LibAnswers, statistics are more granular in that LibAnswers provides data for questions CSI librarians answered for (1) users from CSI, (2) users from other colleges in the CUNY co-op and (3) users from the global co-op. Monthly totals for each of these categories were compiled. As can be seen from the data tables, the previous platform Question Point only held data for the totals for (1) number of questions asked by CSI users answered by anyone and (2) number of questions answered by CSI librarians for any user. These data could be compared for the 2014-2020 period. The percentages of CSI users' questions answered by CSI librarians are available only from June 2020 onward.

\section{Notes on student access to virtual chat reference}

During the pre-COVID period, the CSI Library's 24/7 chat box could be accessed from a box embedded on the main homepage and from the Ask-a-Librarian page under Help [21]. At the onset of the campus closure, the CSI Library added that chat widget as a pull-out tab on all website pages. The chat box was also added to every CSI librarian's research guides (LibGuides). Therefore, the results that follow compare as best as possible sets of data under inherently shifting conditions, albeit conditions prompted by the pandemic itself.

\section{Limitations}

The pandemic has upended the traditional scholarly publishing process, bringing a need for clinically applicable research to be made available quickly. The author suggests that there is also merit in adding to the scholarly conversation around service design and delivery at this particular point in time as library workers and administrators endeavor to adapt services to meet the needs of users in the current moment. Furthermore, the author suggests that there is value in publishing this near-term study rather than waiting to complete a longer-term study assessing and reflecting on the changes implemented. This is the initial part of that longer study, which allows practitioners to see conditions at another institution now.

\section{Discussion}

Trends in questions asked

If one compares the remote learning/work-from-home pandemic period of mid-MarchDecember 2020 (nine and a half months, Chart 7, Table 7) to past academic years (SeptemberMay, 9 months, Charts 1-4, Tables 1-4) the results are quite illuminating. This "pandemic year" includes the summer months (generally low usage months), and yet those nine months would represent the CSI Library's highest "year" ever in both number of questions CSI users asked and number of questions CSI librarians answered. During this period CSI users asked 971 questions (Chart 7), which is a $12.15 \%$ increase from the highest comparable academic year (September-May) of 2014/2015, when the figure was 865 (contained in Chart 1).

If we treat the early pandemic months as part of the academic year 2019/2020, on the other hand, the total number of chat questions asked by CSI users was 609 (Chart 4). That represents a $59 \%$ increase from the previous academic year of 2018/2019 (Chart 3), which saw only 482 CSI 
user questions and was our lowest year. Comparing academic year 2018/2019 to the abovementioned "pandemic year," would change this percentage even more strikingly to a $101 \%$ increase in usage. We have clearly seen a very large increase in our chat usage in the COVID-19 period.

Virtual reference amid campus closure

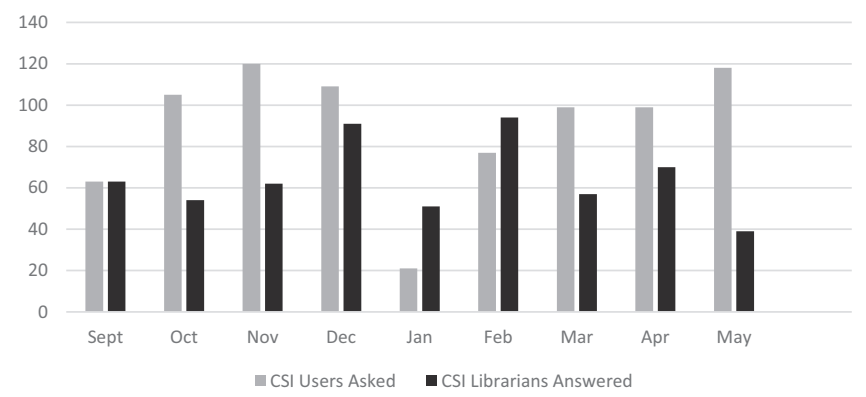

Chart 1. 2015/2016: Chat questions asked/ answered by CSI

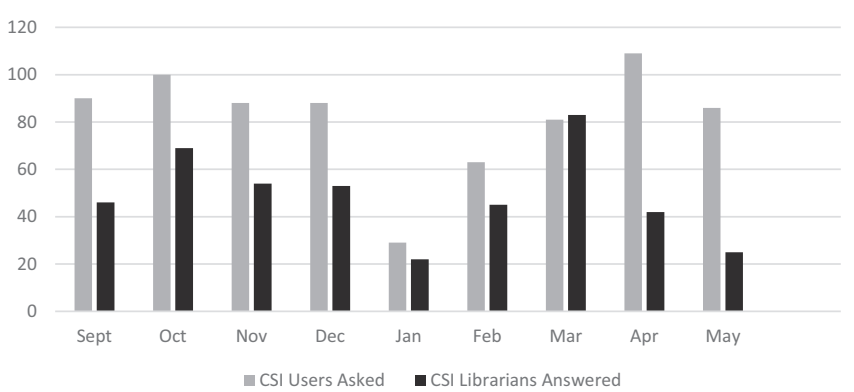

Chart 2. 2017/2018: Chat questions asked/ answered by CSI

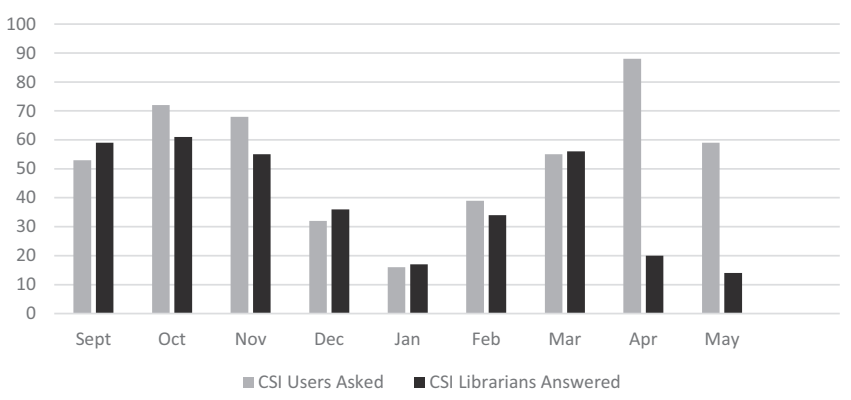

Chart 3. 2018/2019: Chat questions asked/ answered by CSI

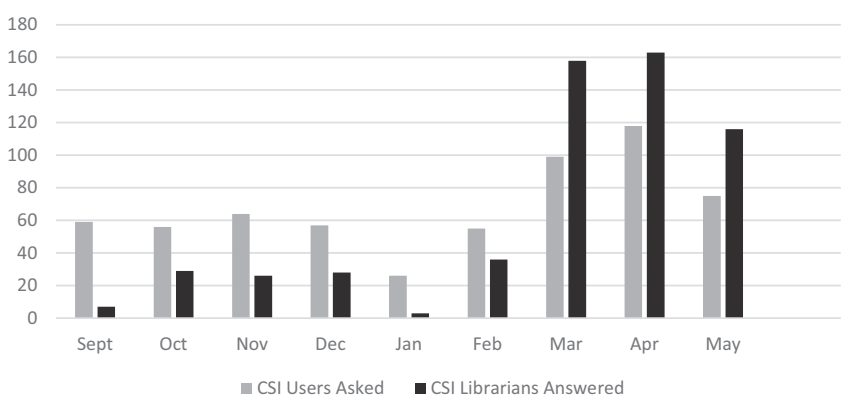

Chart 4. 2019/2020: Chat questions asked/ answered by CSI 


\section{RSR}

\section{Chart 7.}

March-December 2020: Chat questions asked/ answered by CSI

\section{Chart 5.}

Summer 2019: Chat questions asked/ answered by CSI

\section{Chart 6.}

Summer 2020: Chat questions asked/ answered by CSI

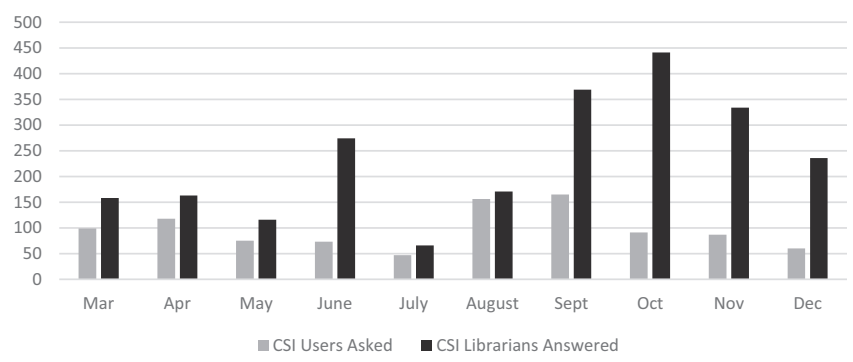

CSI Library also had its two highest ever monthly question totals over this pandemic period. August (156 questions) and September (165 questions) of 2020 (Chart 7) exceeded all months since chat statistics began in 2014. The previous monthly record was 120 questions originating from our users in November 2015 (Chart 1). Of the 156 questions answered in August, 54 of these were between August 26 and 31 . August 26 was the first day of classes.

When considering that the summer months' trend toward lower chat numbers in general, comparing Summer 2019 (Chart 5) to Summer 2020 (Chart 6) provides useful information. In June, July and August of 2019 CSI users asked a total of 65 questions. In the same period in 2020 , CSI users asked 276 questions. This is an increase of $324 \%$ between summers. As noted, our second highest number of questions asked was seen in August 2020.
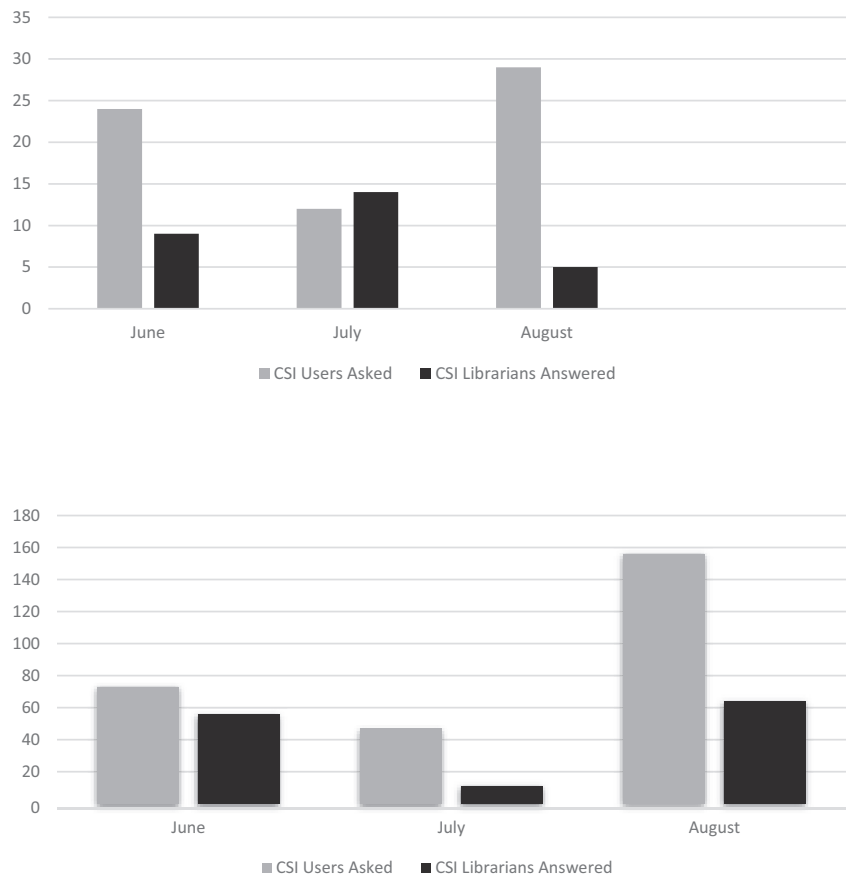
In September-December of 2020 (Chart 7), the Fall semester and half of the 2020/2021 academic year, CSI Library's virtual chat had 403 questions from our users, which is two-thirds of the previous entire academic year's total of 609 (2019/2020, Chart 4). Therefore, CSI Library is on track for a possible record break of the previous academic year's high of 865 . The same period last year, September-December 2019 (Chart 4), had a total of 236 questions from CSI users, which means CSI Library's chat service saw an increase of 70\% in usage from Fall 2019 to Fall 2020 semesters. The summer and the fall of 2020 have been unprecedented semesters. It is abundantly clear how beneficial virtual chat reference is to CSI Library's users at this time.

\section{Trends in questions answered}

As mentioned, with the transition to LibAnswers in June of 2020, during the pandemic, new data became available that was not provided by Question Point. Previously, only the total number of questions that CSI librarians answered for all users was known. Since the switch to LibAnswers, the number of CSI users' questions that CSI librarians answer can be found and shown as a percentage of the total number of questions that CSI librarians answer for all users of the co-op. From June to December 2020 (Chart 8, Table 8), CSI users asked between 15 and $25 \%$ of the total number of questions CSI librarians answered, except for August, when CSI user questions accounted for 37\%. Over the entire six-month period, CSI users asked $23.3 \%$ of the questions CSI librarians answered (441 answered for our users of 1,891 questions answered total). The percentage of CSI users' questions that CSI librarians answered varies enormously from a low of $23 \%$ (11 of 47 questions) in July, to a high of $97 \%$ (89 of 91 questions) in October. Over the six-month period, it was 64\% (441 answered of 679 questions asked by our users). This new data point will be useful to analyze into the future and allow us to better focus on our own users' needs.

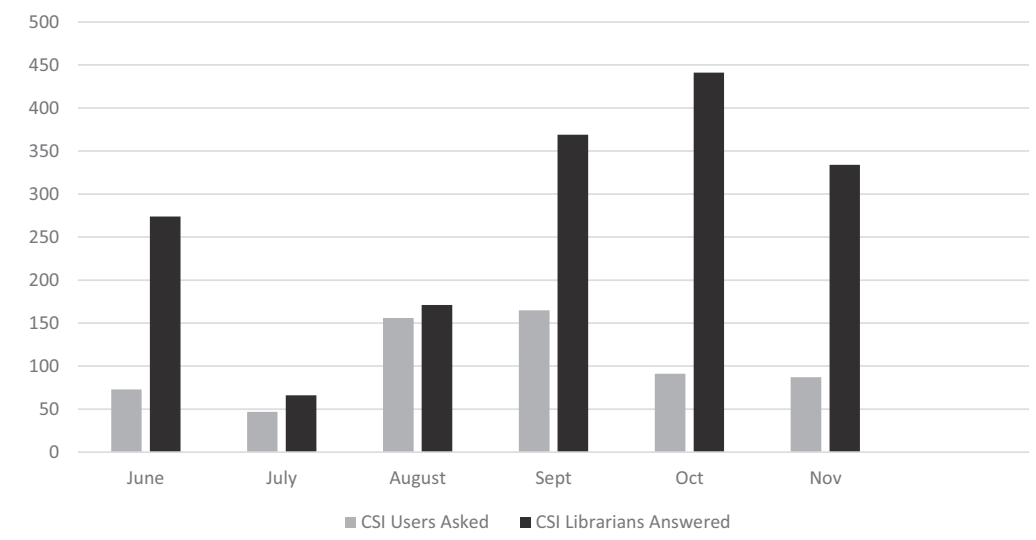

Chart 8. June-December 2020 (LibAnswers): Chat questions asked/ answered by CSI

CSI librarians' answering percentages have been extremely high. As noted, to remain in good standing within the LibAnswers cooperative, CSI librarians should aim to answer $75 \%$ of the number of questions CSI users ask. CSI reference librarians have been exceeding that by a large number since the pandemic started. In 2017/2018 (Table 2) CSI's answering percentage was $59.8 \%$. In 2018/2019 (Table 3), it was $73 \%$. In $2019 / 2020$ (Table 4), this percentage jumped to $92 \%$ because of the bump from the work-from-home period starting in March. And for the pandemic period of MarchDecember 2020 (Table 7) that number soared to $239.7 \%$, a total of 2,328 questions answered. 
RSR

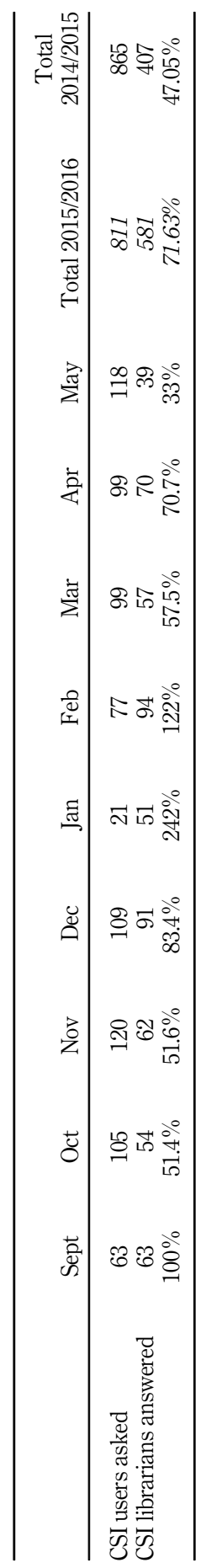

Table 1.

2015/2016: Chat 


\begin{tabular}{lcccccccccc}
\hline & Sept & Oct & Nov & Dec & Jan & Feb & Mar & Apr & May & Total 2017/2018 \\
\hline CSI users asked & 90 & 100 & 88 & 88 & 29 & 63 & 81 & 109 & 86 & 734 \\
CSI librarians answered & 46 & 69 & 54 & 53 & 22 & 45 & 83 & 42 & 25 & 439 \\
& & & & & & & & & & $59.8 \%$
\end{tabular}

Table 2. 2017/2018: Chat questions asked/ answered by CSI

\begin{tabular}{lcccccccccc}
\hline & Sept & Oct & Nov & Dec & Jan & Feb & Mar & Apr & May & Total 2018/2019 \\
\hline CSI users asked & 53 & 72 & 68 & 32 & 16 & 39 & 55 & 88 & 59 & 482 \\
CSI librarians answered & 59 & 61 & 55 & 36 & 17 & 34 & 56 & 20 & 14 & 352 \\
& & & & & & & & & & $73 \%$
\end{tabular}

Table 3. 2018/2019: Chat questions asked/ answered by CSI

\begin{tabular}{lrrrrrrrrrr}
\hline & & & & & & & & & & Total \\
& Sept & Oct & Nov & Dec & Jan & Feb & Mar & Apr & May & $2019 / 2020$ \\
\hline CSI users asked & 59 & 56 & 64 & 57 & 26 & 55 & 99 & 118 & 75 & 609 \\
CSI librarians answered & 7 & 29 & 26 & 28 & 3 & 36 & 158 & 163 & 116 & 566 \\
& & & & & & & & & & $92.03 \%$
\end{tabular}

Table 4. 2019/2020: Chat questions asked/ answered by CSI

\begin{tabular}{|c|c|c|c|c|c|}
\hline & June & July & August & Total & Table 5. \\
\hline CSI users asked & 24 & 12 & 29 & 65 & 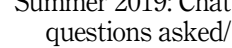 \\
\hline CSI librarians answered & 9 & 14 & 5 & 28 & answered by CSI \\
\hline
\end{tabular}

\begin{tabular}{|c|c|c|c|c|c|}
\hline & June & July & August & Total & Table 6. \\
\hline CSI users asked & 73 & 47 & 156 & 276 & questions asked/ \\
\hline CSI librarians answered & 274 & 66 & 171 & 511 & answered by CSI \\
\hline
\end{tabular}


RSR

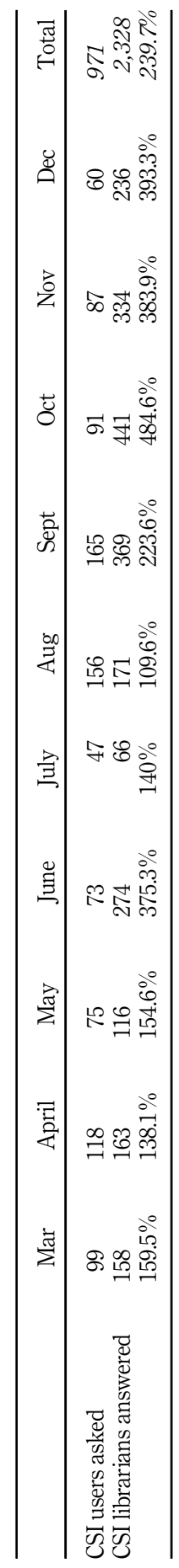

Table 7.

March-December 2020

(pandemic closure, all

virtual reference): Chat

Questions Asked/

Answered by CSI 


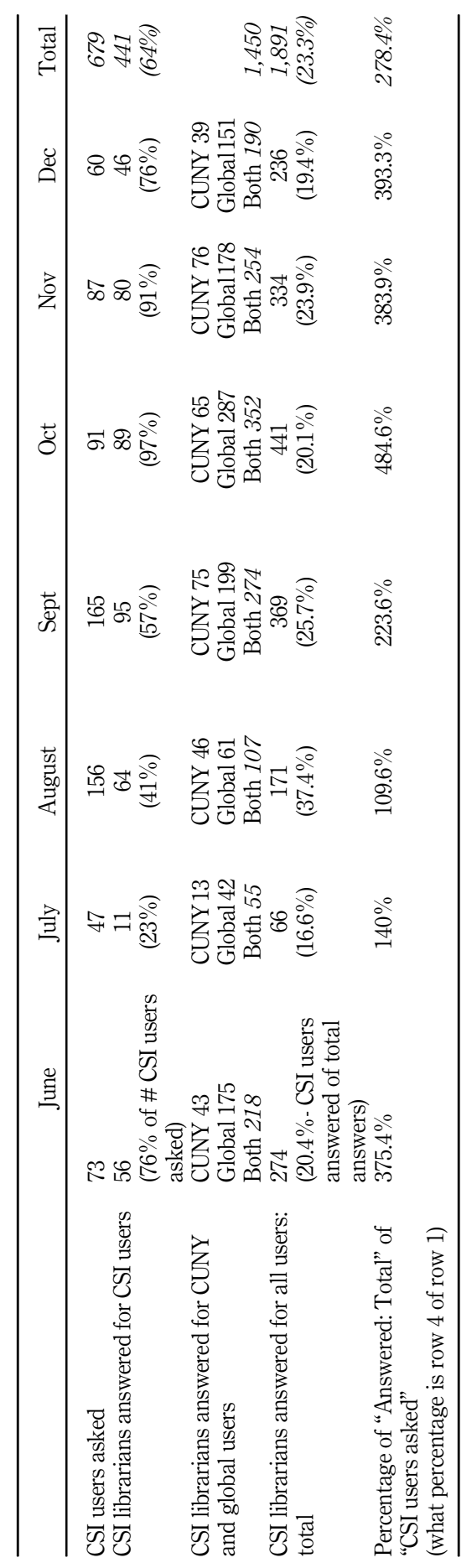

Virtual reference amid campus closure

Table 8. June-December 2020

(LibAnswers): chat questions asked/ answered by CSI (new granularity) 
LibAnswers includes an additional feature that the CSI reference librarians have taken advantage of - a ticketing solution for referring questions to users' home libraries when questions are picked up by a non-CSI cooperative librarian, or when CSI librarians are offline. 255 tickets have been submitted and answered since the inception of LibAnswers, and its ticket system, between May 29, 2020 and the end of the year. Because Question Point did not include this feature, the author cannot compare statistics between the two, but as a matter of increased user access, it is worth mentioning as an additional boon to service. Tickets are mostly created by other librarians in the cooperative answering CSI users, to trigger a follow-up from a librarian at the user's home institution. The only available comparable data point could be the CSI Library's reference email account that receives some traffic (82 emails for 2019/2020, 60 for 2018/2019). The new platform and the focus on virtual reference in the pandemic has allowed the CSI Library to increase its service points beyond what was previously available at the desk. The CSI Library will have to consider how to integrate these access points into workflow when the campus reopens.

\section{Changes to virtual reference}

After reflecting on these data, the Coordinator of Reference and the Chief Librarian reexamined the virtual reference service and staffing model. The department's full-time librarians, all of whom conduct reference shifts, discussed the service at a monthly meeting. Due to CSI librarians' high answering percentage and the increase in CSI students using the service, it was concluded that dividing the labor between part and fulltime librarians might allow the reference service to focus on and prioritize CSI students who need help the most, especially considering the community-oriented mission of the CSI Library.

As of January 2021, CSI's full-time librarians are monitoring only the local CSI queue or chat department. The goal is that CSI librarians will answer a higher percentage of CSI users' questions. Local institutional knowledge should hopefully provide them with more accurate answers more quickly than the ticket referral service of the co-op. In an examination of "the relationship between user satisfaction and teaching" in a regional university library consortial chat service, Barrett et al. concluded that "consortial chats that included teaching led to higher user satisfaction" (2020, p. 194). Might teaching be more likely to occur when the users' institution's librarians answer the chat? Would we be more able to apply our instructional pedagogy to reference interactions originating from our own users, thereby making virtual reference more satisfying? In the next months, the CSI librarian team will continually assess this new model to determine if there are even more incisive routes to directly assisting our student body with its particular needs.

\section{Conclusion}

Conducting a case study of our virtual reference usage has provided invaluable data. Clearly, the virtual chat service has seen a considerable increase in use during the pandemic period, due to the physical campus closure. The CSI Library has determined actions from these data including altering the old method of creating the reference desk schedule in favor of fewer but longer virtual shifts, and splitting up monitoring of our three chat queues (local CSI, CUNY and global). The hypothesis is that this variation in monitoring will hopefully result in a better service for CSI users and be a more efficient and better use of CSI librarians' time. The next step is to assess these changes at either the end of this academic year or a period after reopening in the Fall semester. The author will determine if CSI librarians are answering a larger proportion of CSI users' questions than previously, and to what degree. Qualitative data will be elicited from librarians about the value of this change to their experience of reference service. Chat transcripts will be analyzed, and users will be surveyed postchat. Efforts to promote the service will continue. It is envisioned that two reports 
from the field will update this case study - the first on the virtual reference data after changes of January 2021 onward, to the end of the academic year, or to the end of the campus closure period, and the second post-reopening. In the last few months, there have been several calls issued by peerreviewed journals in our field for special issues focused on adapting to providing services during the COVID-19 pandemic. We look forward to a growing body of research on service design and use during-and-post-pandemic from which practitioners can draw.

During this time, we suggest that practitioners think about virtual chat service after reopening and prepare for new challenges ahead. What implications might the pandemic have on user expectations after reopening? Will our colleges and universities increase focus on online offerings and if so, what effect might that have on user expectations of virtual library services? Reference and user services librarians can use this period to revitalize their commitment to virtual reference service and to reflect on reframing their service ethic for this moment and for the postpandemic higher education environment.

\section{Notes}

1. https://www.cuny.edu/about/

2. https://www.csi.cuny.edu/about-csi/president-leadership/office-president/strategic-plan

3. https://library.csi.cuny.edu/about/vision-mission-values

4. https://applications.csi.cuny.edu/Institutional_Profile/SemesterEnroll_Profile.html, Compare to borough statistics here: https://www.census.gov/quickfacts/richmondcountystatenis landboroughnewyork

5. For more information see, https://www.csi.cuny.edu/about-csi/institutional-effectiveness/ institutional-research/institutional-profile and https://applications.csi.cuny.edu/Institutional_ Profile/SemesterEnroll_Profile.html

6. https:/www.cuny.edu/wp-content/uploads/sites/4/page-assets/about/administration/offices/oira/ institutional/data/current-student-data-book-by-subject/ug_student_profile_f19.pdf

7. https://www.library.csi.cuny.edu/home

8. There are various reasons for this though one, no doubt, is our student profile and the concern that a user in need of reference help may not have their needs met. The author is aware of discussions within the profession on the division between credentialed and uncredentialed library workers, and on the 2018 ballot measure regarding ALA's executive director requiring an MLS, http://www.ala. org/news/press-releases/2018/04/ala-announces-election-ballot-measure-results

9. https://library.csi.cuny.edu/eresources

10. https://annehays.commons.gc.cuny.edu/critical-thinking-on-remote-learning-teaching-abibliography-of-ideas/

11. https://ibrary.csi.cuny.edu/blog/CSI-Library-Statement-on-Textbooks/Required-Course-MaterialsAccess-During-COVID-19

12. https://springshare.com/news/libanswers-qp.html\#: :text=DUBLIN $\% 2 \mathrm{C} \% 20$ Ohio $\% 2 \mathrm{C} \% 2031 \%$ 20May $\% 202019$,reference $\% 20$ software $\% 20$ for $\% 20$ libraries $\% 20$ worldwide.

13. https://ojs.lboro.ac.uk/JIL/announcement/view/38

14. https://www.emeraldgrouppublishing.com/journal/rsr/anti-racist-action-libraries

15. The author also searched the institution's discovery layer and Google Scholar.

16. http://www.ala.org/tools/Covid/guidance-protocols

17. https://acrl.libguides.com/pandemic/reopening

18. https://www.ifla.org/Covid-19-and-libraries 
20. Academic year 2016/2017 is currently inaccessible as it is on a computer on campus and cannot be retrieved by the author.

21. https://ibrary.csi.cuny.edu/help/ask

\section{References}

Anderson, R., Fisher, K. and Walker, J. (2021), "Library consultations and a global pandemic: an analysis of consultation difficulty during COVID-19 across multiple factors", The Journal of Academic Librarianship, Vol. 47 No. 1, pp. 1-13, doi: 10.1016/j.acalib.2020.102273.

Archer-Helke, C., Kahl, C., Kremer, C., Stevens, C. and Wolfgang, L. (2021), "The pandemic made me do it: changing public services", Internet Reference Services Quarterly. doi: 10.1080/10875301.2021. 1891183.

Barrett, K., Logan, J., Pagotto, S. and Greenberg, A. (2020), "Teaching and user satisfaction in an academic chat reference consortium", Communications in Information Literacy, Vol. 14 No. 2, pp. 181-204, doi: 10.15760/comminfolit.2020.14.2.2.

Beveridge, A., Weber, S. and Beveridge, S. (2011), "Librarians in the United States from 1880-2009", OUP Blog, June 20, available at: https://blog.oup.com/2011/06/librarian-census/\#: :text=A\% 20Feminine $\% 20$ Profession,percent $\% 20$ of $\% 20$ the $\% 20$ librarian $\% 20$ population.

Brown, L. (2020), "Recalibrating librarians' service ethic in the COVID-19 pandemic: towards a mutually empowering framework", in Qualitative and Quantitative Methods in Libraries (QQML) Special Issue Libraries in the Age of COVID, pp. 95-106, available at: http://qqmljournal.net/index.php/qqml/article/view/634.

Campbell, A., Dumond, J. and Fink, P. (2020), "Virtual(ly) overnight: providing resources and services in the era of COVID-19", in Qualitative and Quantitative Methods in Libraries (QQML) Special Issue Libraries in the Age of COVID, pp. 55-66, available at: http://qqml-journal.net/index.php/ qqml/article/view/651.

Dar, M. (2020a), "Ramping up remote reference", Library Journal, April 1, 2020, available at: https:// www.libraryjournal.com/?detailStory = ramping-up-remote-reference.

Dar, M. (2020b), "How COVID-19 has transformed reference services for public and academic libraries", Library Journal, November 10, 2020, available at: https://www.libraryjournal.com/? detailStory=how-Covid19-has-transformed-reference-services-for-public-academic-libraries.

Dodd, L. and Kotaska, R. (2020), "Expanding chat reference during COVID-19", Library Journal, September 2, 2020, available at: https://www.libraryjournal.com/?detailStory=expanding-chatreference-during-Covid-19-peer-to-peer-review.

Ettarh, F. (2018), "Vocational awe and librarianship: the lies we tell ourselves", in In the Library with the Lead Pipe, available at: http:/www.inthelibrarywiththeleadpipe.org/2018/vocational-awe/ \#identifier_18_8690.

Galvan, A. (2015), "Soliciting performance, hiding bias: whiteness and librarianship", in In the Library with the Lead Pipe, available at: http://www.inthelibrarywiththeleadpipe.org/2015/solicitingperformance-hiding-bias-whiteness-and-librarianship.

Hathcock, A. (2015), "White librarianship in blackface: diversity initiatives in LIS", in In the Library with Lead Pipe, available at: http://www.inthelibrarywiththeleadpipe.org/2015/lis-diversity/.

Honma, T. (2005), “Trippin' over the color line: the invisibility of race in library and information studies", InterActions: UCLA Journal of Education and Information Studies, Vol. 1 No. 2, available at: https://escholarship.org/uc/item/4nj0w1mp.

Howes, L., Ferrell, L., Pettys, G. and Roloff, A. (2021), "Adapting to remote library services during COVID-19”, Medical Reference Services Quarterly, Vol. 40 No. 1, pp. 35-47, doi: 10.1080/02763869. 2021.1873616. 
Koos, J.A., Scheinfeld, L. and Larson, C. (2021), "Pandemic proofing your library: disaster response and lessons learned from COVID-19”, Medical Reference Services Quarterly, Vol. 40 No. 1, pp. 67-78, doi: 10.1080/02763869.2021.1873624.

Lindsay, J.M., Petersen, D., Grabeel, K.L., Quesenberry, A.C., Pujol, A. and Earl, M. (2021), "Mind like water: flexibly adapting to serve patrons in the era of COVID-19", Medical Reference Services Quarterly, Vol. 40 No. 1, pp. 56-66, doi: 10.1080/02763869.2021.1873622.

Mars, P. (2018), "Gender demographics and perceptions in librarianship", School of Information Student Research Journal, Vol. 7 No. 2, available at: http://scholarworks.sjsu.edu/slissrj/vol7/ iss $2 / 3$.

Radford, M.L., Costello, L. and Montague, K. (2021), "Surging virtual reference services: COVID-19 a game changer", College and Research Libraries News, Vol. 82 No. 3, pp. 106-107, 113, available at: https://crln.acrl.org/index.php/crlnews/article/view/24847.

Rafiq, M., Batool, S.H., Ali, A.F. and Ullah, M. (2021), "University libraries response to COVID-19 pandemic: a developing country perspective”, The Journal of Academic Librarianship, Vol. 47 No. 1, pp. 1-10, doi: 10.1016/j.acalib.2020.102280.

Schlesselman-Tarango, G. (2016), "The legacy of lady bountiful: white women in the library", Library Trends, Vol. 64 No. 4, pp. 667-686.

Simpson, T. (2020), "No library is an Island: how a consortium of academic libraries transitioned to a remote-only service model", Qualitative and Quantitative Methods in Libraries, Vol. 9 No. 3, pp. 511-520.

Vogus, B. (2020), "Examining virtual reference services in academic libraries", Public Services Quarterly, Vol. 16 No. 4, pp. 249-253, doi: 10.1080/15228959.2020.1818664.

Walsh, B. and Rana, H. (2020), "Continuity of academic library services during the pandemic: the University of Toronto Libraries' response”, Journal of Scholarly Publishing, Vol. 51 No. 4, pp. 237-245, doi: 10.3138/jsp.51.4.04.

Weeks, A., Houk, K.M., Nugent, R.L., Corn, M. and Lackey, M. (2020), “UNLV health sciences library's initial response to the COVID-19 pandemic: how a versatile environment, online technologies, and liaison expertise prepared library faculty in supporting its user communities", Medical Reference Services Quarterly, Vol. 39 No. 4, pp. 344-358, doi: 10.1080/02763869.2020.1826197.

\section{Corresponding author}

Maureen Garvey can be contacted at: maureen.garvey@csi.cuny.edu

For instructions on how to order reprints of this article, please visit our website:

www.emeraldgrouppublishing.com/licensing/reprints.htm

Or contact us for further details: permissions@emeraldinsight.com 